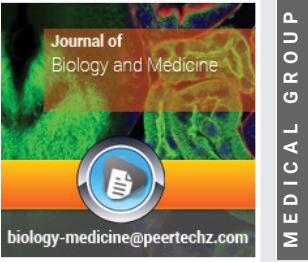

\title{
Improving Quality of Education in Extreme \\ Adversities-The case of Libya
}

\author{
${ }^{1}$ Authority of Natural science Research and Technology, Libya \\ ${ }^{2}$ Scientific Council of Laboratory Medicine/ Medical Specialty council, Libya \\ ${ }^{3}$ Quality and Performance Evaluation Office University of Tripoli, Tripoli, Libya \\ ${ }^{4}$ National Center for Accreditation of Health Establishments, Libya
}

Aisha Nasef ${ }^{1,2 *}$, Mohamed A Al-Griw ${ }^{3}$ and Adel El Taguri ${ }^{4}$
Received: 19 March, 2020

Accepted: 29 May, 2020

Published: 30 May, 2020

*Corresponding author: Aisha Nasef, Authority of Natural science Research and Technology, Libya, Tel: + 218910419561; E-mail: Nasef@doctor.com

Keywords: Medical; Education; Universities; Quality assurance; Accreditation; Libya

https://www.peertechz.com

Check for updates

\section{Introduction}

History of medical education in Libya spans over a period of 50 years. Medical education started in faculty of medicine at Benghazi in 1970, and at Tripoli in 1973. Both medical schools performed their main core function and their graduates provided good health services locally and abroad. However, the medical schools did not keep up with the immense changes that medical education experienced over the last two decades with inclusion of research and community services within their main core function [1-3],

Education of professionals must be adapted to practice in order to meet needs and demands of the population and the health systems that serve them. Currently, the role of medical schools needs to be redefined and regulated in a world where specialization is becoming a requirement to practice. Medical schools need to transform their specialist training into a community-oriented education in accordance with World Health Organization (WHO) and World Federation for Medical Education (WFME) recommendation, to reorient medical education to meet current challenges [3-5].

Reflecting the importance of the interface between medical education and the healthcare delivery sector, the WHO/WFME Strategic Partnership was formed in 2004 to improve medical education. In 2005, the partnership published guidelines for accreditation of basic medical education. The WHO/WFME Guidelines recommend the establishment of proper accreditation systems that are effective, independent, transparent and based on medical education-specific criteria [5-7].
An important prerequisite for this development is initiation and use of WFME Global Standards program in 1997 in all six WHO/WFME regions as a basis for quality improvement of medical education [7].

Global Standards for quality Improvement divided the standards into basic standards and quality development standards. Basic standards, which are 106,should be fulfilled by all institutions involved in medical education. Standards for quality development, which are 90, serve as an incentive for development and as a leverage for improvement. Standards are defined in these two levels for each of the different domains (Text box 1).

\footnotetext{
Text Box 1: Medical Education Global Standards for Quality Improvement.

1. Mission and objectives

2. Educational program and principles

3. Assessment of educational outcomes

4. Students

5. Academic staff/faculty

6. Educational resources

7. Monitoring and evaluation of programs and courses

8. Governance and administration

9. Continuous renewal.
}

\section{Current status of medical education in libya}

In spite of initial promising level, quality of medical education in Libyan universities progressively declined due to many reasons (Table 1).

Faculty of Medicine in Libyan international medical university was the only medical school getting a provisional 
Table 1: Causes of deterioration of Medical education in Libyan medical schools.

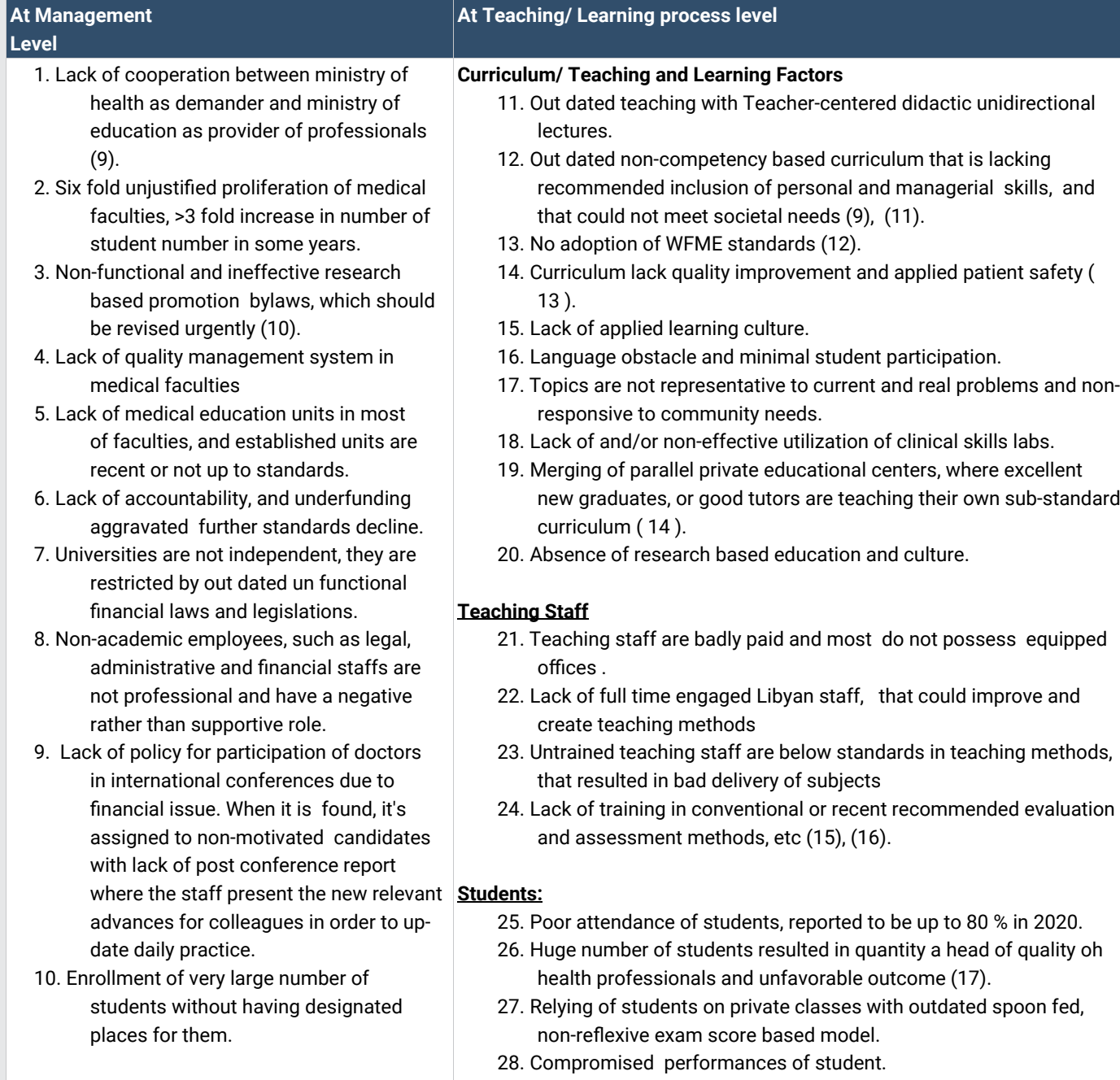

29. Lack of sufficient facilities; equipped study and library halls. Lack of standard and up-dated references, books and journals.

30. Non-availability of internet to promote study and research.

31. Absent or limited or inaccessible inscription to medical scientific journals.

32.An iconic shortcoming of medical schools represented in presence of photocopy office to produce copies of lectures, to use it as a source of reading!

33. A Repelling environments with shortage of appropriate hygienic facilities

34. Lack of an encouraging environments and facilities such as; canteen (with healthy affordable meals), sport halls or stadium.

35. Lack of medical research culture for students and staff.

36. Un availability of state of arts hospitals with skilled staff and advanced technology suitable for good standard education.

8. Compromised performances of student

institutional and program accreditation on 2017. Of note, Libya is neither included in countries served by agencies with Recognition Status by WFME, nor among countries with application in progress [8].

\section{Consequences of declining teaching level}

The decline in the quality of medical education led to exclusion of Libyan medical schools from the annual publications of international rankings, to loss of confidence in Libyan universities, consequent loss of confidence in Libyan doctors, with further decline in medical services.

Benghazi medical schools achieved $33 \%$ of basic standards in an assessment performed in 2018, followed by Tripoli medical schools achieved $22 \%$. Other medical schools achieved less than $5 \%$ of basic standards [9].

Most current medical graduates are under-qualified due to sub-standard medical education, with resulting lack of professionalism, absent scientific attitude, weak creativity and inability to play a role in health advocacy. Suboptimal medical education was aggravated by enrolling of large numbers of students despite non-readiness of medical schools. As a result a lot of Libyans seek treatment in neighboring countries and in
Europe with increase of financial costs and economic burden for both patients and government. In addition, patients pay an additional price because of consequent ineffective and/or incomplete management especially for cancer, trauma and rare diseases.

\section{Road map for accreditaion in libya}

Road to accreditation composed of two phases. First phase is establishment of a national task force for accreditation prepares for establishment of a national system for accreditation. Second phase is establishment of sound Internal Quality Assurance (IQA) system with clear responsibilities at medical universities (Figure 1).

Phase one is composed of the following steps to be taken in order to establish a national system for accreditation for higher educational institutes (Text Box 2). The Quality Assurance Accreditation of Higher Educational institutes (QAAHEI), currently named National Center for Quality Assurance and Accreditation of Educational and Training Institutes (NCQAAETIs), is the only governmental authorized body accrediting and quality assuring the higher educational institutes in Libya. 
Updated strategic plan (2012-2017), addressed all drawbacks such as redundancy, repetition of mission as well as an ambiguity and inconsistency with higher institute mission. However, a very big obstacle facing center is being affiliated to Ministry of Education with possibility of conflict of interest and loss of independency and credibility. Secondly, being subjected to continuous changes of bylaws and management staff, absence of clear regulation, job description and specification. Thirdly, it's currently below standards due to several causes despite being a member of International Network for Quality Assurance Agencies in Higher Education (INQAAHE) and Arab Network for Quality Assurance in Higher Education (ANQAHE) till 2012. Moreover, it's not recognized by WFME yet.

All the higher educational institutes were requested to adapt and implement the standards of quality assurance and accreditation of the Quality Assurance and Accreditation Guide Lines (General Popular Committee Decree \# 430 - 2008). Higher educational institutes have to maintain the minimum requirements for accreditation (Institutional / programs; provisional / final).

Phase two concerning with establishment of sound IQA system at medical schools. This system should have a model QA, responsible for $\mathrm{QA}$, customers charter, continuous monitoring of the implementation of the activity (analysis of previous competences, control of the presence, interim verification, students satisfaction, etc), plan for continuous improvement, attention to customer's satisfaction, determination of vision, mission and goals of the institute, adequate strategic planning and effective action plans to satisfy the goals. General process of Academic Accreditation are shown in (Text Box 3).
Text Box 2: Steps taken for establishment of National Center for Quality Assurance and Accreditation of Educational and Training Institutes

\section{Stage 1: Establishment Stage}

1. 2004: GPC Decree \#141 - 2004 Establishment of Research and Quality Assurance in Higher Education. First Annual Quality Conference.

2. 2005: GPC Decree \#80 - 2005: Executive Committee for QA \& Accreditation.

3. 2006: Establishment of Quality Assurance Accreditation of Higher

Educational institutes by GPC Decree $\quad \# 164-2006$

4. 2006: GPC Decree \#303 - 2006. Forming committee for center management

5. 2006: GPC Decree \#339 - 2006. Approval of organizational structure and organogram.

6. 2007: QA \& Accreditation Guidelines Approval.

7. 2008: GPC Decree \#430 - 2008 Mandated the use of the Guidelines for Assuring the Educational Process.

\section{Stage 2: Launching Stage}

1. 2008: Workshops of Quality Assurance and introduction of quality assurance and accreditation center, and auditing teams formation.

2. 2009: Membership of the Arabic \& International Network

3. 2009: GPC Decree \#129 - 2009 Renaming: Quality Assurance Accreditation of

Educational institutes

4. 2009: GPC Decree \#134 - 2009 Reform of organizational structure and organogram

5. 2010: GPC Decree \#18 - 2010 Authorization of evaluation of for Quality Assurance in educational institute.

6. 2010: Meeting with quality assurance mangers in Libyan universities.

7. 2010: Decree from Minster of Health to consider 2010 as the Year of Quality in Libyan Universities.

8. 2010: Report on public and private higher education institutes in Libya.

\section{Stage 3: Reform Stage.}

1. 2011-2014: Manual of Quality Assurance and Accrediation of Higher Education Institute and models of institutional and Program Accreditation

2. 2012-2017: Strategic Plan of Quality Assurance and Accrediation of Education Institute.

3. 2012: Report of National Center for Quality Assurance and Accreditation of Educational and Training Institutes-2012.

4. 2013: Report of challenges facing Quality Assurance and performance evaluation offices

5. 2013: Report of exploratory visits of 13 auditing team consist of 130 academic staff, listing challenges, weakness and corrective practice as well as

6. 2016: : Minister of Higher Education and Scientific Research: Decree \#674 - 2016. Approval of guiding procedure and accreditation standards for higher educational institute, and up-dating institutional and program accreditation standards(18)

Text.Box 3: General process of Academic Accreditation

1. Establishment of National Center for Quality Assurance and Accreditation of Educational and Training Institutes (NCQAAETIs).

2. Rising awareness and dissemination of quality culture.

3. Conduction of self-study by IQA department for monitoring measures.

4. Auditing (This forms a key criterion for the external institutional assessment)

5. Result of accreditation evaluation at both institutional and program level.

6. Follow-up.

7. Re-evaluation

\section{Establishement of internal quality system at medical universities}

Quality and innovation of medical education in Libyan medical schools is needed, to identify weak area, to enforce education, to graduate competent care giver medical students, to have an international standards of services to retain public trust, to prevent financial and brain drain. Quality medical education can be established in three steps (Table 2).

Self-study and description through assessment of current status such as; facilities, student's number/staff number,

Citation: Nasef A, Al-Griw MA, Taguri AE (2020) Improving Quality of Education in Extreme Adversities-The case of Libya. J Biol Med 4(1): 006-011. 
students (attendance, participation, accomplishments, etc.), teaching staff (self-management, professionalism and ethics, skills, knowledge and commitment), resources and availability of sufficient material for practical teaching, uses of advanced technology in teaching such as (clinical skills laboratories, 3D models, telemedicine conferences, etc), examination method and out-come.

Second component of self-study is bench marking with international faculties for modernization of medical schools, through evaluations and revisions to compete with other similar institutions around the world and to ensure delivery of quality medical education for Libyans and inclusion of Libyan medical schools/universities in the annual publications of international rankings.

Initation of IQA through adoption of recommendation and action plan for changes by finding an alternative approaches. Integrative teaching/learning approaches could help keeping a track between basic and clinical sciences and sequentially link all major components of the teaching/learning process. These approaches permit minimum curriculum that meets agreedupon learning objectives, thus avoiding unnecessary repetition, saving time money and effort of medical school staff and takes into consideration community needs. Implementation of national quality assurance is composed of institutional and program accreditation process $[22,23]$. Both institutional and program accreditation scope are listed (Table 3). Accreditation process of both institutional and program are shown in (Text Box 4).

Implementation would start by specifying criteria and standards which have to be met, by an official agency of accreditation body in order to achieve a positive

Table 2: Steps of establishment of sound IQA system at medical universities.

\section{STEPS} Components

1) Self study:

- Self assessment and description.

- Assessment of current status and SWOT analysis.

Step 1 Conduction of self study

To assess quality and effectivness of services.

2) Bench-marking

3) Recommendation and Action Plan

1) Adoption of recommendation and Action Plan For Further Enhancemnt.

Step 2 Initation of QA in Medical

2) Having an alternative teaching/ learning approaches and adoption of evidence based medicine (19).

3) certification of quality management systems of educational institutions.

Implementation of national quality assurance according to standard guidelines

1) Accreditation of educational institutions (Institutional accreditation).

2) Accreditation of degree programmes (Program accredetation) (20).

Evlauation, supervision of the accredited educational institutions and accredited degree program for of ten standrads (20), (21).
Table 3: Scope of Institutional and Program accreditation.

\begin{tabular}{|l|c|c|}
\hline & Institutional Accreditation & Program Accreditation \\
\cline { 3 - 3 } & Components & Components \\
\hline 1 & Planning & Planning and administrative organization. \\
\hline 2 & Educational resources \& program, & educational resources and program: \\
\hline 3 & Academic staff. & Academic staff. \\
\hline 4 & Student affair. & Student affair. \\
\hline 5 & Facilities and educational resource. & Facilities and educational resource. \\
\hline 6 & Scientific research, & Scientific research. \\
\hline 7 & Community services & Community services \\
\hline 8 & Quality assessment \& continual & Quality \\
improvement & $\begin{array}{c}\text { assessment and continual } \\
\text { improvement }\end{array}$ \\
\hline 9 & Leadership and governance. & \\
\hline
\end{tabular}

Text Box 4: Process of Institutional and Program Accreditation. Institutional Process of Accreditation

Program Process of Accreditation

1) An application from concerned institution 1) An application from concerned for accreditation.

2) Completion of application form on questions related to Mission and vision, institution for accreditation.

2) Completion of application form on questions related to:

student's number/staff number, teaching a Information on the institution.

b. Information on the program

c. Study plan.

Financial and administrative affairs

infrastructure, security and Quality assurance office.

3) External audit by the NCQAAETIs

4) Application form with report of audit team's report permit NCQAAETIs to provides provisional institutional accreditation

5) Continues monitoring and reaccreditation

Table 4: Criteria and Standards to be fulfilled in order to be achieve a positive external assessment by an official agency of accreditation body.

\begin{tabular}{|c|c|c|}
\hline $\begin{array}{l}\text { A- Input } \\
\text { standards: }\end{array}$ & B- Process standards & C-Outcome standards \\
\hline $\begin{array}{l}\text { Institution and } \\
\text { budget } \\
\text { Physical } \\
\text { arrangement } \\
\text { Staff } \\
\text { Planning }\end{array}$ & $\begin{array}{l}\text { Curricular demands } \\
\text { Levels of competences to be achieved } \\
\text { Quality assurance system } \\
\text { Teaching should be effective, tailored to } \\
\text { student's needs. } \\
\text { Examinations should assess the actual } \\
\text { student's achievements; } \\
\text { Transparent teaching plan, curriculum, } \\
\text { and learning outcomes } \\
\text { Analysis of students needs } \\
\text { Teaching equipment } \\
\text { Use of effective and differentiated } \\
\text { methodologies Guidance } \\
\text { Examination procedures and evaluation.. } \\
\text { Examination standards, etc. }\end{array}$ & $\begin{array}{l}\text { Minimum } \\
\text { performances to } \\
\text { achieve efficiency } \\
\text { and effectiveness as } \\
\text { trusted professionals. }\end{array}$ \\
\hline
\end{tabular}

External assessment. The criteria and standards for accreditation vary widely between different countries and according to the specific field of training (Table 4).

Auditing should involve evaluation of 10 standards, and result should be $\geq 60 \%$ for each standard, and overall result should be $\geq 70 \%$ (Table 5) [22].

\section{Conclusion}

Evidence based medicine, clinical reasoning, self-directed critical thinking and problem solving approach are mandatory 
Table 5: Basic Standards for Institutional and Program Accreditation.

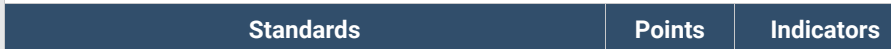

Institutional Standards

Mission and Objectives.

Governance and administration system.

Educational program/Program evaluation.

Academic staff/ Faculty

Educational resources.

Student /Student assessment.

Infrastructure and facilities.

Financial affairs.

Scientific research.

Continuous renewal

\begin{tabular}{|c|c|c|}
\hline Educational program. & 1200 & 100 \\
\hline Academic staff. & 400 & 34 \\
\hline Educational resources. & 180 & 18 \\
\hline Student affair. & 400 & 40 \\
\hline Infrastructure and facilities. & 150 & 17 \\
\hline Quality assurance \&continual improvement & 300 & 29 \\
\hline
\end{tabular}

in order to acquire better retained and usable knowledge in a clinical context through student-centered teaching, and team interpersonal skills promotion. Adoption of new and high standards methods of teaching such as 3D models $[24,25]$, along with updated responsive teaching materials are mandatory and represent pre-requirements for accredited medical schools

Accreditation, a risk-reduction strategy, is not an aim by itself but it is a tool for self-recognition, continuous improvement of pedagogical skills and a guide to reach out for the standards as a way to achieve academic excellence, which is the real added value of all the operations, we do.

Therefore, the accreditation and continuous quality improvement in medical education is crucial to adjust medical education to improve the current status of health service system and to prepare qualifying doctors for the needs and expectations of their essential clients, i.e the community they serve.

Accreditation and continuous quality improvement are expected to ensure training in era of information technologies in order to help doctors cope with the explosion in medical and scientific knowledge and technology, and to be lifelong learners.

Stakeholders in National Center for Quality Assurance and Accreditation should work urgently to acquire mandatory state of art performance and excellency of execution. It would be advisable, for Quality Assurance and Accreditation center to consider a mandate for issuing practice license for all future public and private medical school, to ensure availability of quality requirements since establishment. Then they should consider closing severely underperforming medical schools.
A check list of standard requirements including inputs, process, outcomes, institutional and program quality, financial cost should be prepared as first step. This should be followed by a review of all medical schools according to these selected criteria. Subsequently, tough but needed decisions are needed to close medical schools with low quality standards in order to ensure efficiency and effectiveness of medical education.

National Center for Quality Assurance and Accreditation achieved remarkable progress despite all inconvenient circumstances. However, there is still a long way to go. Auditing own performances and outcomes, implementing standards of quality, hiring competent employees, collaboration with international centers and having a national plan to have medical schools with international standards in near future.

\section{References}

1. Al-Areibi A (2019) Medical education in Libya: Challenges, hopes, and recommendations. Libyan Int Med Univ J 4: 3-9. Link: https://bit.ly/2ZPWor2

2. Ambarek MS (2010) The need for Quality Management Systems in Libyan universities. Libyan J Med 5: 10. Link: https://bit.ly/2ZRExA2

3. Karle H (2008) World Federation for Medical Education Policy on international recognition of medical schools' programme. Ann Acad Med Singapore 37: 1041-1043. Link: https://bit.ly/3dhGiKv

4. (2012) Health education: theoretical concepts, effective strategies and core competencies: a foundation document to guide capacity development of health educators. World Health Organization, Regional Office for the Eastern Mediterranean. Link: https://bit.ly/3dhMDWq

5. WFME (2015) Global Standards for Quality Improvement: Basic Medical Education. Link: https://bit.ly/3cdQCII

6. WHO (2015) Global Strategy on Human Resources for Health. Workforce 2030. Link: https://bit.ly/2TR902c

7. Karle H (2007) Global Standards and Accreditation in Medical Education: A View from the WFME. Acad Med 81: S43-S48. Link: https://bit.ly/2XFDxMw

8. Countries served by agencies with Recognition Status (Map). Wfme. Link: https://bit.ly/2XgLI8u

9. The Libyan Health System: Study of Medical and Allied Health Education and Training Institutions. Ministry of Health, Health Information and Documentation Center 2018. Link: https://bit.ly/36Hznld

10. Promotion Criteria. University of Toronto. Link: https://bit.ly/2zyBMsF

11. Frank J, Snell L, Sherbino J. Can MEDS (2015) Physician Competency Framework. Royal College of Physicians and Surgeons of Canada. Link: https://bit.ly/2yPNaQu

12. Standards. Wfme. Link: https://bit.ly/3gurtX0

13. Wong BM, Etchells EE, Kuper A, Levinson W, Shojania KG (2010) Teaching quality improvement and patient safety to trainees: A systematic review. Acad Med 85: 1425-1439. Link: https://bit.ly/2ZR3Qly

14. Alsubaie M (2015) Hidden curriculum as one of current issue of curriculum. J Educ Pract 6: 125-128. Link: https://bit.ly/2zzV0OD

15. Schüttpelz-Brauns K, Narciss E, Schneyinck C, Böhme K, Brüstle P, et al. (2016) Twelve tips for successfully implementing logbooks in clinical training. Med Teach 38: 564-569. Link: https://bit.ly/2MesQeu

16. Berk RA (2009) Using the 360 degrees multisource feedback model to 
evaluate teaching and professionalism. Med Teach 31: 1073-1080. Link: https://bit.ly/2TUkvRo

17. Service Availability and Readiness Assessment (SARA) Survey 2017. Link: https://bit.ly/2ZNKjCE

18. Link: https://bit.ly/3cjokpE

19. Brauer DG, Ferguson KJ (2015) The integrated curriculum in medical education: AMEE guide no. 96. Med Teach 37: 312-322. Link: https://bit.ly/3dt86f

20. Link: https://bit.ly/2zJ79ke

21. Http://.www.who.int/hrh/documents/WFME_report.pdf
22. WFME Recognition Programme. Wfme. Link: https://bit.ly/2MaJ08C

23. The Education System in Libya: Recommendations for Development. Draft Report Submitted by UK NARIC 2012

24. Tejo-Otero A, Buj-Corral I, Fenollosa-Artés F (2020) 3D Printing in Medicine for Preoperative Surgical Planning: A Review. Ann Biomed Eng 48: 536-555. Link: https://bit.ly/2XIvIFV

25. Lim KHA, Loo ZY, Goldie SJ, Adama JW, Mcmenamin PG (2016) Use of 3D printed models in medical education: A randomized control trial comparing 3D prints versus cadaveric materials for learning external cardiac anatomy. Anat Sci Educ 9: 213-221. Link: https://bit.ly/3gxxr9E
Discover a bigger Impact and Visibility of your article publication with Peertechz Publications

\section{Highlights}

* Signatory publisher of ORCID

* Signatory Publisher of DORA (San Francisco Declaration on Research Assessment)

* Articles archived in worlds' renowned service providers such as Portico, CNKI, AGRIS, TDNet, Base (Bielefeld University Library), CrossRef, Scilit, J-Gate etc.

* Journals indexed in ICMJE, SHERPA/ROMEO, Google Scholar etc.

* OAI-PMH (Open Archives Initiative Protocol for Metadata Harvesting)

* Dedicated Editorial Board for every journal

* Accurate and rapid peer-review process

* Increased citations of published articles through promotions

* Reduced timeline for article publication

Submit your articles and experience a new surge in publication services (https://www.peertechz.com/submission).

Copyright: (c) 2020 Nasef A, et al. This is an open-access article distributed under the terms of the Creative Commons Attribution License, which permits unrestricted use, distribution, and $r$ eproduction in any medium, provided the original author and source are credited.

Citation: Nasef A, Al-Griw MA, Taguri AE (2020) Improving Quality of Education in Extreme Adversities-The case of Libya. J Biol Med 4(1): 006-011. 